\title{
The Ladies Vanish?
}

\section{American Sociology and the Genealogy of its Missing Women on Wikipedia}

\author{
Wei Luo \\ Stanford University, USA \\ weiwluo@stanford.edu \\ Julia Adams \\ Yale University, UsA \\ julia.adams@yale.edu
}

\begin{abstract}
Hannah Brueckner
New York University Abu Dhabi, United Arab Emirates

hb63@nyu.edu
\end{abstract}

\begin{abstract}
Many notable female sociologists have vanished from the canonical history of American sociology. As the most influential crowd-sourced encyclopedia, Wikipedia promises - but does not necessarily deliver - a democratic corrective to the generation of knowledge, including academic knowledge. This article explores multiple mechanisms by which women either enter or disappear from the disciplinary record by analyzing the unfolding interaction between the canonical disciplinary history of sociology and Wikipedia. We argue that the uneven representation of women sociologists as (1) remembered, (2) neglected, (3) erased or, finally, (4) recovered is shaped by the emerging interactional space of knowledge production.
\end{abstract}

\section{Keywords}

Wikipedia - sociology - disciplinary memory - knowledge - gender - big data encyclopedia - canon 
"People just don't vanish and so forth."

"But she has."

"What?"

"Vanished."

"Who?"

"The old dame." ...

"But how could she?"

"What?"

"Vanish."

"I don't know."

"That just explains my point. People just don't disappear into thin air." ALFRED HITCHCOCK, The Lady Vanishes (1938) ${ }^{1}$

In comparison to many academic disciplines, sociology has been relatively open to women since its founding, and seems increasingly so. Yet many notable female sociologists are missing from the public history of American sociology, both print and digital. The rise of crowd-sourced digital sources, particularly the largest and most influential, Wikipedia, seems to promise a new and more welcoming approach. Might some women who have vanished from expert-led canonical disciplinary histories resurface on Wikipedia or its counterparts? What is the relationship between widely-accepted versions and new digital representations of the discipline's early founders and contributors, in the increasingly blended space of sociological knowledge? As part of the more general questions of how we can detect why some significant women vanished from the disciplinary record, and the conditions under which they resurface, therefore, this paper addresses a specific genealogical problem: how those early women scholars whom one would have expected to have been recorded and acknowledged are nonetheless missing in action, un- or underrepresented in canonical disciplinary history and/or Wikipedia.

The disciplinary history of sociology has until recently been narrated by experts in the field, and mainly for a professional, field-related audience. It has

1 Script by Sidney Gilliat and Frank Launder, based on Ethel Lina White's The Wheel Spins (Penguin 1966 [1936]). 
often been told in the form of a recognizably Enlightenment story that traces the emergence and development of knowledge, beginning with classical figures who first authored it and extending into an ever-more scientifically rigorous and demographically inclusive future. A modernizing arc is discernable, it is argued, even if disciplinary history is inflected by internal resistance to it (Jackson 2000). A second tradition treats the rise of sociological knowledge more impersonally, rendering it as part and parcel of an expanding repertoire of works and institutions - academic, governmental, or non-governmental and non-academic - specializing in research, teaching, training, and consultation (Bourdieu 1984; Shils 2006). This alternative vision of an evolving formation or a more heterogeneous aggregate of materials includes knowledge about the social sciences themselves, and forecasts more conflictual and less directional incorporation of marginalized individuals, viewpoints or institutions. Third and finally are analyses of the discipline that stress the active construction and reconstruction of core principles and of the canon itself (Parsons 1937; Merton 1968; Connell 1995; Adams, Clemens and Orloff 2005).

The ongoing turbulence of the internet age cuts across all these ways of understanding disciplinary development, seeming to offer new possibilities of representation and new risks of informational loss and degradation. Crowdsourced encyclopedias, online dictionaries and compendia, blogs, and other types of digital platforms do provide easier access to an enormous amount of diverse information for the general public and experts alike. These platforms are also increasingly interacting with previous forms of knowledge and information, including in ways that sometimes occlude and deform more traditional expert-authored sources; this is the case even when the experts themselves contribute to the new platforms. ${ }^{2}$ Of these, Wikipedia - the world's largest and most used online reference encyclopedia - is also the most important. ${ }^{3}$ Although academics may be disdainful of Wikipedia when it comes to professional knowledge, American sociologists and disciplinary representatives have intensively interacted with the emergent information bank. In 2011, for example, the American Sociological Association (ASA) launched a Sociology in Wikipedia Initiative to promote the involvement of professional sociologists

2 Some of these challenges are features of virtually all digitization. They include problems of data loss and corruption, unintended consequences such as inadvertent deletion via misspecified algorithms etc., which pervade the structure of digitally-mediated knowledge.

3 As of September 2017, English-language Wikipedia contained 5,485,590 articles with $7,078,811,347$ page views per month. It had 29,111 monthly active editors who created 641 articles per day (report by Wikimedia, published on October 12, 2017: https://stats.wikimedia .org/EN/SummaryEN.htm). These numbers indicate Wikipedia's constitutive role in some parts of the contemporary knowledge bank. 
in contributing to Wikipedia and to increase its legitimacy as a source of reference in the classroom. ${ }^{4}$ In addition, many ongoing professional projects have specifically sought to understand or actively improve Wikipedia's ability to produce sociological knowledge about the role of women in the discipline itself. ${ }^{5}$

Wikipedia's major mode of knowledge production, crowdsourcing, "... is the act of taking a job traditionally performed by a designated agent (usually an employee) and outsourcing it to an undefined, generally large group of people in the form of an open call." (Howe 2008) The editable web pages that comprise Wikipedia integrate a database system for storing and modifying information, which encourages participants to collaborate on publishing facts about wideranging subjects, and with relatively low technical requirements (Black 2008). Editing histories are recorded in the system and are putatively accessible to any user, and users can make changes to a current page by attaching an explanation justifying such content modifications. This relatively user-friendly operation and interaction platform should make Wikipedia an effective tool for both recording and generating sociological knowledge in a potentially global collaborative effort.

The discipline of sociology is curiously configured on Wikipedia, however. The crowdsourcing mechanism generates inclusive but also strange and incoherently organized categories under an umbrella project loosely labeled "sociology" (Adams and Brueckner 2015). The list of living "American Sociologists" on Wikipedia in August 2014, for example, contained a mixture of notable academics (about 6o\%); social activists and social workers; motivational speakers, and numerous people who had little if any connection with the discipline (ibid.), while many people professionally recognized as sociologists were absent. Although unsatisfactory in its current form, however, Wikipedia offers genuinely new opportunities for the improvement and diffusion of academic knowledge and more adequate scholarly representation. By delineating the interaction between canonical disciplinary history and crowd-sourced online platform, we endeavor to illuminate the contrasting pathways by which women either enter or are excised from disciplinary knowledge.

4 See http://www.asanet.org/sites/default/files/savvy/footnotes/novi1/wikipedia_1111.html (accessed on February 28, 2018).

5 See http://www.asanet.org/sites/default/files/savvy/footnotes/septoctı/wikipedia_o914.html (accessed on February 28, 2018). After three years of the ASA Wikipedia Initiative, which aimed to narrow the gender gap in the demographics of Wikipedia editors, more women students participated in editing Wikipedia pages. 
Problems of gender representation exist in both traditional disciplinary histories of sociology and in Wikipedia. Unlike in the natural and physical sciences, in which the gender distribution is highly skewed and women have historically made up a much smaller proportion of scholars within the disciplines, women have composed a substantial part of the American sociological community from the discipline's early years. That means that they 'have a chance' to be remembered, whether on traditional or digital sources. From the 1920s to 196os, $16 \%$ of all U.S. doctoral degrees in sociology were awarded to women; by 1974, this number had increased to $30 \% .{ }^{6}$ In sharp contrast to the significant presence of women as students, professors, and practitioners of the field, however, academic sociology typically passes over important female participants when reconstructing its own past.

There is an important counter-corpus of scholarship that attempts to discover and reassess women's contributions to sociology (Broschart 2008; Deegan 1991, 1995, 2002, 2014; Feagin 2001; Grant, Stalp, and Ward 2002; Hill and Hoecker-Drysdale 2003; Hoecker-Drysdale 1990, 2008; Lengermann and Niebrugge 2007; McDonald 1995, 1998; Sklar 1995, Thomas 2005). Despite this sizable literature, few if any female sociologists, particularly from earlier eras, are incorporated into the teaching of the canonical interpretation of the field (Terry 1983, Thomas and Kukulan 2004, Thomas 2005). And because the successful institutionalization of the discipline has also dovetailed with the exclusion and marginalization of racial and ethnic minorities in the definition of a sociological canon, women of color are particularly scarce. The social theory books that emphasize women's contribution to the discipline are less central, ${ }^{7}$ while scholars engaged in the labor of bringing women back into the sociological canon are themselves largely eclipsed in most sociological texts. The contrast between women's presence in the development of sociology and their

6 Data retrieved on June 17, 2016 from Century of Doctorates: Data Analyses of Growth and Change: U.S. PhD's - Their Numbers, Origins, Characteristics, and the Institutions from Which They Come (1978), App. A, p. $117 \mathrm{ff}$. Note that the number does not include women who are not categorized as sociologists but should be, such as those who worked at the emergent boundary of sociology and social work.

7 According to Google Scholar, for example, Sociological Theory (2001) by Bert N. Adams, R.A. Sydie is cited 103 times and Liberation Sociology (2016) by Joe R. Feagin, Hernan Vera, and Kimberley Ducey 213 times, in comparison to more mainstream social theory textbooks, e.g. Ritzer and Stepnisky (2017) Modern Sociological Theory cited 3505 times and Wallac and Wolf (1999) cited 857 times. (Pages accessed on November 18, 2017.). 
persistent absence from the canon and most disciplinary histories certainly calls for closer examination.

The gendered characteristics of knowledge in Wikipedia are also strongly marked. The editorial composition is skewed, ${ }^{8}$ and the entries themselves are criticized for their inadequacy with respect to the representation of notable women. ${ }^{9}$ For sociology, for example, four of the 17 female presidents of the American Sociological Association (ASA) cannot be found on Wikipedia. ${ }^{10}$ Or consider the doctoral graduates from the department of sociology at the University of California-Berkeley. ${ }^{11}$ The department's list includes $5^{2}$ women, from 1955 to 2007, who have published books derived from their dissertations. Forty-eight of the $5^{2}$ have an internet presence elsewhere than on Wikipedia. These women worked or work in universities or research institutes and held or hold leading positions in professional organizations including the American Sociological Association, the National Science Foundation, and so forth. Only nine of these women can be found on Wikipedia. ${ }^{12}$

Overall, this study opens up a number of comparative questions, one of which we address centrally here. Comparing women sociologists' print and digital representations, this paper focuses on differences among women, their varying paths of scholarly categorization in the earlier years of one discipline, and the ongoing canonical legacies with which that discipline still contends. We leave aside for the moment why women might be missing "more" than comparable men, or why the discipline of sociology might differ from other disciplines when it comes to representing women. By illuminating the genealogy of disciplinary memory and forgetting of notable women in the early years of American sociology, we hope to shed light on these comparative questions in the landscape of gender and scholarly representation.

8 An Editors Survey conducted by the Wikimedia Foundation in 2011 reported that $91 \%$ of editors were male. See https://meta.wikimedia.org/wiki/Research:Wikipedia_Editors_ Survey_2011_April (accessed February 28, 2018). Responding to the criticism of systemic gender bias in Wikipedia, the Wikimedia Foundation has launched initiatives to expand female editorial input.

9 See for example http://dirkriehle.com/uploads/2013/04/wikipedia-sexism.pdf (Accessed February 28, 2018).

10 We searched both Wikipedia and the list posted on the ASA website (http://www.asanet .org/about-asa/how-asa-operates/elected-officers), generating this result. The search was originally conducted on February 26, 2016 and reaffirmed on February 28, 2018.

11 See http://sociology.berkeley.edu/books-dissertations. The search of the University of California-Berkeley list was conducted on January 10, 2016.

12 These women include thirty academics with professorships at major universities (18 full professors; 10 associate professors; 2 assistant professors). 
In the following sections, we review the integration of women into the documented history of sociology. By comparing Wikipedia's list of sociologists with traditional encyclopedia sourcebooks, we propose a typology delineating the new interactional space of knowledge formation. We then use the typology as a tool to indicate key cases of notable sociologists missing on Wikipedia and highlight the paths they traced on the way to digital obscurity. The focus is on chains of disciplinary representation which, we argue, has now become an emergent interaction between the digital and canonical forms of scholarly knowledge and history of the discipline.

Although Wikipedia currently depends more on the canonical disciplinary version of history than vice versa, the interdependency of these two kinds of textual rendition is an object of investigation here, and a way to gain further traction on the problem of 'missing women'. The textual representations of women sociologists, as a medium that bridges women's lived experience and the discursive world of concepts and abstractions, exhibit a high level of variability in terms of both quantity and quality. The readily quantifiable differences (such as length of text; number of sources; demographics of contributors) and the more qualitative variation within the written representation (including accuracy of information; the relative authoritativeness of sources; the agency of the female scholar; the embeddedness of the text in larger context, etcetera) are susceptible to mapping and explanation.

From a historical perspective, the presence or absence of a woman from written documents can be pinpointed in one or more layers in the pathways of knowledge formation. As Figure 1 below shows, there are a number of processes that shape the current representation of a woman on scholarly Wikipedia, and more generally in the discipline of sociology.

Each female sociologist's (i) work would have been assessed by contemporary commentators (ii), who interacted with it via the cultural understandings and institutional arrangements and struggles of the time. These assessments filtered into scholarly papers, reviews, editors' comments, personal correspondence, and non-academic records and representations of all sorts. They become forms of evidence that later scholars and investigators (iii) use as they select historical individuals in service of a particular narrative about the development of the discipline. Less accredited academic or intellectual work may drop out at this stage, possibly to resurface later. The ongoing product of these narratives forms the academic history of the discipline. 


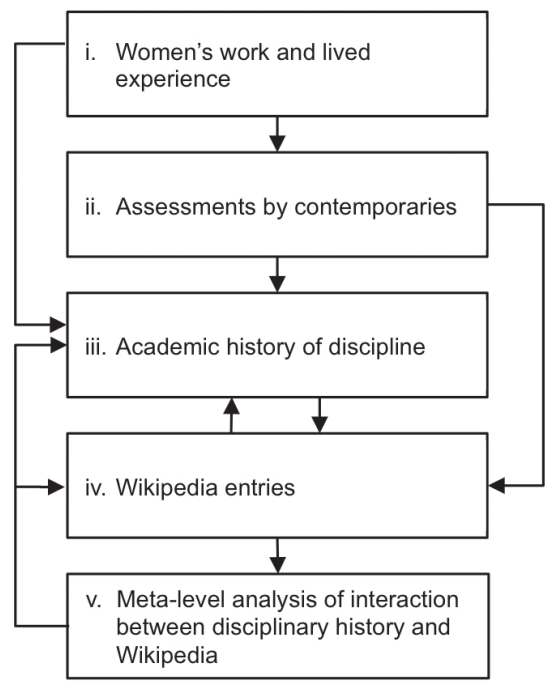

FIGURE 1

Key vectors of knowledge formation

Here the epistemological fissures begin to widen. For though it is likely that an editor of a crowd-sourced digital platform (iv) will rely on existing academic histories or other texts directly influenced by them to generate or edit entries about disciplinary figures, those entries may instead arise from an earlier point on the chain of representation, for example in primary archival sources. If so, however, the rules ensure that they are less likely to survive deletion challenges (of which more below). And finally, meta-level analysts (v), like ourselves, who have access to both academic histories and Wikipedia or other digital platforms, seek to understand - and perhaps intervene in - the mechanisms that produce specific forms of representation of sociologists in our contemporary world.

Two cross-cutting dimensions, or four logical possibilities, emerge as the expert-led print and crowd-sourced digital worlds intersect. First, a female sociologist may or may not have appeared in academic histories. The history of an established discipline is commonly written, and peer-reviewed for quality, by experts in the field. Such experts rely on their own experience and intellectual judgment to construct a narrative about the discipline, using primary and secondary documents, including those created about the events experienced. The problem of a "missing" woman can therefore be located in the decisional moments of the woman's contemporaries - particularly fellow scholars and experts - and those of the disciplinary history writers and editors of a later period.

The second dimension to take into account is that a woman sociologist may or may not have a Wikipedia page of her own. Wikipedia entries are 
mostly written by non-specialists; if an entry chances to be written by experts in the field, their anonymity deemphasizes markers of authority or expertise. The selection of topics is also constrained by Wikipedia's standard of so-called "notability." According to the English-language Wikipedia notability guidelines, ${ }^{13}$ a topic is presumed to merit a stand-alone article if "it has received significant coverage in reliable sources that are independent of the subject." The guidelines further specify that significant coverage means "no original research is needed to extract the content," and that sources should be secondary sources, "as those provide the most objective evidence of notability." From an academic scholarly perspective, these guidelines are odd to say the least, but they were originally designed to prune redundant information and obviate self-promotion. In the area of scholarly biography, however, these criteria potentially exclude individuals whose contributions should have been but have not been adequately acknowledged in their own fields. In Wikipedia guidelines, nonetheless, this type of selective negligence is justified in the following terms:

If a subject has not been covered outside of Wikipedia, no amount of improvements to the Wikipedia content will suddenly make the subject notable. Conversely, if the source material exists, even very poor writing and referencing within a Wikipedia article will not decrease the subject's notability.

WIKIPEDIA, Notability, https://en.wikipedia.org/wiki/Wikipedia:Notability

In addition to the flaws embedded in relying so strongly on "secondary sources" to decide whether a person merits an entry, Wikipedia's notability standards are also problematic in terms of the decision-making process. Discussion among Wikipedia contributors is disproportionately based on assertion rather than arguments that engage the substance of the scholarship under scrutiny; many discussions are guided by personal preference, at best, undermining the reliability of entries (Adams and Brueckner 2015). Moreover, if Wikipedia strictly implemented its own notability standards, it could not serve as a means to recover and reevaluate lost academic knowledge if, for example, an individual or topic had been inadequately treated in disciplinary history. If procedures are strictly adhered to, its particular mode of collaborative authoring and vetting of articles at best cumulates existing accredited knowledge; it has generally

13 See https://en.wikipedia.org/wiki/Wikipedia:Notability (accessed on February 28, 2018). 
abandoned underappreciated, yet valuable, information, as well as elevating knowledge contingent upon editors' potentially biased judgments.

The combination of the two crosscutting dimensions of textual representation generate four possible categories, displayed in Figure 2.

Academic History

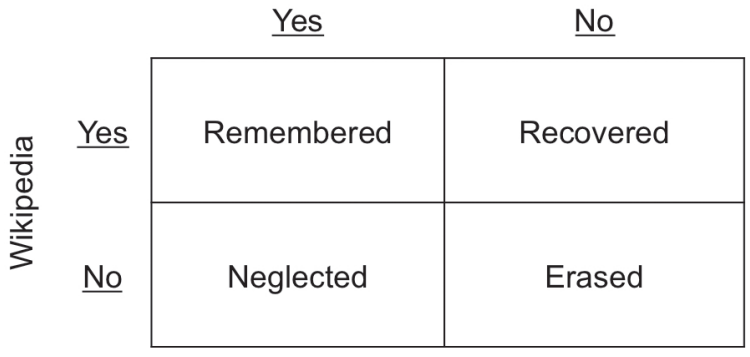

FIGURE 2 Types of canonical textual representation

At the level of individual experience, the four categories are not mutually exclusive. Plenty of people experience, and indeed biographically traverse, more than one situation over the course of their lives. But by capturing the center of gravity of their personal histories from the perspective of the present, the framework helps us render both the distinctive situations that the missing women encountered and their contemporary memorialization. In what follows, we will first illustrate the four categories identified in Figure 2 using examples of women sociologists' structured experiences as well as the perceived diversity and malleability of their paths in life.

The baseline category - which we designate as 'remembered' - includes women scholars who occupy important public positions in the discipline's history and who also have a Wikipedia presence, for instance Jessie Bernard, Ida B. Wells, or Jane Addams and the Chicago Hull House circle. The existence of this category enables us to clarify the other three, all of which are to one degree or another 'missing'.

The 'neglected' category embraces those who are acknowledged in academia and have appeared in canonical histories of sociology but are missing from Wikipedia. This is a situation in which expert knowledge could help fill the gap in Wikipedia's more popular representation. This can only occur if editors are persuaded to use more diverse and trustworthy academic sources, rather than other unvetted online information, as seems to be the case at present. An example of a 'neglected' woman sociologist is Frances Donovan, who was rediscovered by feminist scholars in the 1980 s and whose books, published 
between 1919 to 1938, are substantively reviewed in the American Journal of Sociology (AJs). ${ }^{14}$ The online sphere does not yet reflect the reassessment of her status by the contemporary sociological community. ${ }^{15}$ As of January 2017, the 'neglected' group also included eminent American Sociological Association presidents of more recent times, including Joan Huber, Maureen T. Hallinan, Cynthia Fuchs Epstein, and Cecilia L. Ridgeway.

A variation includes women sociologists who are present on Wikipedia but not acknowledged as sociologists per se. Their pages therefore lack information on any contribution to the discipline. These women were professionally trained as sociologists and practiced their craft in diverse settings, including social service agencies, research and policy-making groups, and urban settlement houses. In academic history, however, research universities were and are increasingly understood to be the more legitimate worksite. Thus these women have been generally labeled social reformers or social workers, and excluded from the history of sociology as an academic discipline. Wikipedia has inherited this particular tradition of academic history writing. Among the 76 women contributors to welfare reform (Gordon 1992), for instance, thirty-seven are missing on Wikipedia as of this writing, and despite the fact that many had received graduate degrees in sociology, only five were coded as sociologists on the site. Of the eight women scholars who belonged to the "Chicago Women's School of Sociology" as recorded in a biographical sourcebook (Lengermann and Niebrugge 2007: 229-274), just one is listed on Wikipedia as a sociologist.

The category that we call 'erased' includes those women scholars who should have been recognized in the field or who were recognized by contemporaries, but who have been deleted from the discipline's history and, unsurprisingly, do not have a Wikipedia presence. We use the term 'erased' to emphasize the process of women scholars having been "written out" of academic history (Lengermann and Niebrugge 2007: 3), oftentimes quite deliberately. These women were widely recognized by their contemporaries as outstanding scholars and actively served a sociological community through publishing, teaching and involvement in organizations and professional associations.

14 See Barbara Celarent, American Journal of Sociology, Vol. 115, No. 3 (November 2009), pp. 984-990; Kurent, Heather Paul. Frances R. Donovan and the Chicago School of Sociology: a case study in marginality. 1982. The 2017 publication of Barbara Celarent's collected essays, prefaced by Andrew Abbott, is likely to result in Frances Donovan's shifting from the 'neglected' to what we dub the 'recovered' category.

15 The lag could be attributed to her having been overshadowed by the famous journalist and presenter of the same name, which eliminated Donovan the sociologist from online search results. 
Pauline V. Young's experience illustrates the workings of this category. Young was an important woman scholar of the Chicago School who was at the time of this paper's writing undocumented in both canonical disciplinary histories and Wikipedia. She was cited in a recollection of the Chicago School in the 1920 and 1930 s by another sociologist, Ruth Shonle Cavan. There Young figures as one of the early practitioners of participant observation, or ethnography, in the United States. She received a doctorate in sociology from the University of Chicago. Her culminating graduate work - Pilgrims of Russian-Town (1932) was a classic of this new research method (Cavan 1983) and her work has been cited in a canonical disciplinary history as an outstanding example of ethnographic studies produced by the School (Bulmer 1984: 4). Nevertheless Pauline V. Young and her scholarly contributions have vanished from the discipline. We could find only scant secondary information on her remarkable publication record - including five articles in the American Journal of Sociology or American Sociological Review alone - and an unfinished chronology of her early career. ${ }^{16}$ In contrast to Young's virtual absence from academic history and the world of the virtual encyclopedia, all of her male colleagues at the University of Chicago who conducted similar ethnographic work during the same time period, and who are mentioned alongside Young in Cavan's recollection, have their own Wikipedia pages. ${ }^{17}$

The reconstruction of 'erased' women in academic history and on Wikipedia is much more difficult than retrieving those in the 'neglected' category. The foremost challenge is an acknowledgment - in some cases a re-acknowledgment, as women make their way in and out of the record depending on histories of deletion and restoration - by the contemporary academic community of the important contribution of these early women sociologists. Careful research may then enable us to regain some of the lost information about the women themselves, as well as on the development of the discipline. However, Wikipedia's test of significance, which favors existing online exposure, creates further barriers to retrieving the missing women for the collective stock of knowledge.

Finally, with the category of 'recovered' women, we suggest that there is at least a possibility, embedded in Wikipedia's crowdsourced approach to academic knowledge, of reintroducing the discipline's vanished women and reasserting their place in intellectual history. Such cases are difficult to identify but

16 See http://www.swarthmore.edu/SocSci/rbannisı/SocWomen/Sources/Young.sources.html (accessed on February 28, 2018. The page was last updated in 2002.).

17 See Cavan (1983), pp.414-415. These scholars include Paul G. Cressey, Walter Reckless, Nels Anderson, Frederic Thrasher, and Harvey W. Zorbaugh. 
illuminate the continuing utopian potential of mass knowledge generation in a digital age. This category is possible when Wikipedia editors consult previously marginalized sources in academic history, instead of relying solely on canonical history. Annie Marion MacLean's Wikipedia page is one exemplar. While she was not properly recognized as a sociologist in the existing historiography of the Chicago School, her Wikipedia page depicts her as an important contributor to the discipline. MacLean's Wikipedia page, created on March 14, 2014 and updated October 21, 2017, opens with the statement that she was a pioneering American sociologist and one of the first women to pursue a career in sociology. ${ }^{18}$ The page lays out her connection with both the network of female social scientists in Hull House, the Chicago settlement house founded by Jane Addams and Ellen Gates Starr in 1889, and the major male sociologists of the Chicago School. MacLean's Wikipedia entry successfully presents her as a founding sociologist by using biographical information focusing on her education; sociological and writing career; academic teaching and contributions to administration, and legacy in the discipline. The references that the editor relied on include Deegan's 1991 sourcebook and five academic journal articles on MacLean herself.

The four categories we propose serve as ideal types, and also snapshots of a point in a trajectory at a specific historical moment. The representation of a particular scholar can certainly shift from one category to another over time. In this sense, the categories are useful methodological tools that help us analyze the pathways in the upcoming examples in which women are missing in contemporary digital space. They have implications for better representation of not only the individuals under scrutiny but also the groups and organizations of which the women in question were or should have been (in the counterfactual sense) members.

\section{$4 \quad$ Identifying the Missing Women in Sociology on Wikipedia}

Who are the vanished women? To approach the problem, we use an encyclopedic sourcebook, Mary Jo Deegan's Women in Sociology: A bio-bibliographical sourcebook (1991) ("sourcebook" hereafter), as a comparative frame to scrutinize where leaks occur in the process of knowledge generation. Deegan's sourcebook was an attempt to reinstate and recover significant women

18 Accessed on February 28, 2018. The page includes a hyperlink to "women's Chicago School", although it directs to the page of "the Chicago School (sociology)" that at this writing does not mention MacLean and other women sociologists. 
sociologists that are missing in the sociological canon. Although Deegan's and other similar attempts were sidelined in mainstream academic histories, ${ }^{19}$ the sourcebook serves as a reliable, expert-generated encyclopedic reference for comparison with Wikipedia. It represents the traditional way that encyclopedias assemble knowledge: the entries are produced by experts in specific fields, largely based on reliable primary materials, and are usually peer-reviewed. Wikipedia in contrast signifies the trend of knowledge generation towards "amateurization" (Burke 2012: 273), in which multiple anonymous editors collaborate on the same topic and assemble knowledge through existing online secondary sources.

The list of names in Deegan's sourcebook is gathered from the following sources: (a) recommendation by experts in the study of women, the history of sociology, or a particular subfield; (b) other reference books: Notable American Women; White's Conspectus on Biography; The National Cyclopedia of Biography; The International Encyclopedia of the Social Sciences; Who's Who; and Outstanding Men and Women in the Social Sciences. Deegan then applies formal rules such as Kaesler's Criteria to determine which sociologists should be among the pool of potential candidates and finalizes the list to be included in the sourcebook..$^{20}$ She also identifies women who were the "first" in structural positions in the discipline, to further refine notability claims.

In addition to the sourcebook, we consulted a biographical collection of early women sociologists: A Reader: The Women Founders: Sociology and Social Theory 1830-1930 (2007) ("reader" hereafter) by Patricia Madoo Lengermann and Jill Niebrugge, for more information on the women's life experiences and detailed accounts of their sociological research. The reader selected fifteen women who were "present at and active in the creation of sociology,"21 and all are included in the sourcebook. In order to identify the missing female sociologists, we use Wikipedia's internal search engine to determine whether the names included in the sourcebook and reader appear on Wikipedia and/

19 The book was cited 94 times and not published by an acclaimed university press (citation count accessed on February 28, 2018).

20 See the detailed selection procedure in Deegan (1991), pp. 6-13. Kaesler's five criteria for determining professional sociologists include occupying a chair of sociology and/or teaching sociology; membership in any national sociological society; co-authorship of sociological articles or textbooks; self-definition as a "sociologist"; definition by others as a sociologist. One has to meet all five criteria in order to be adjudged a sociologist.

21 They are Harriet Martineau, Jane Addams, Charlotte Perkins Gilman, Anna Julia Cooper, Ida B. Wells-Barnett, Marianne Weber, Beatrice Potter Webb, Edith Abbott, Grace Abbott, Sophonisba Breckinridge, Florence Kelley, Frances Kellor, Julia Lathrop, Annie Marion MacLean, and Marion Talbot. 
or on the internet elsewhere using Google search. Nearly thirty percent of the women (14 out of 51$)$ in the sourcebook do not have a Wikipedia entry. ${ }^{22}$ As of this paper's writing, we were unable to retrieve any online information about four of these 14 women. Of the remaining 37 individuals in the sourcebook, 11 were acknowledged in 2014 by Wikipedia as sociologists. There is a clear discrepancy between Wikipedia's criteria for defining a sociologist and that of the sourcebook.

Although all 15 women in the reader have Wikipedia entries, the other 23 women that Lengermann and Niebrugge mention appear only in a reader footnote (Lengermann and Niebrugge 2007: 20). These women were also significant participants in the discipline but are not analyzed in detail in the book. Having searched these 23 names on Wikipedia, we note that seven of them lack an entry and only two are labeled as sociologists.

More than half the female sociologists in the early twentieth century who are included in the sourcebook (27 out of 51 ) had some form of connection with the University of Chicago. They were granted their masters or doctoral degrees there; held faculty positions at some point in their academic lives, or were intellectually active within specific circles, such as Hull House. They thereby composed the largest intellectual network in the Wikipedia list when we group individuals by their university affiliations. This situation suggests that the central position of the University of Chicago's sociology department in the first half of the twentieth century makes the women who were embedded in this network more visible than others in academic history and on Wikipedia. It highlights the importance of their having been trained there. By the same token, however, it also made them more vulnerable.

Of the fourteen vanished women whom we can now descry, seven obtained graduate degrees from the University of Chicago. Being embedded in the central network did not make their scholarly influence more tractable, as we will show below. At work, these female scholars sometimes experienced what is now dubbed a 'hostile environment' (as we detail below). At other times, they

22 The missing names are Mary Elizabeth Burroughs Roberts Smith Coolidge, Frances R. Donovan, Lucile Eaves, Margaret Jarman Hagood, Amy Hewes, Joan Huber, Susan Kingsbury, Elizabeth Briant Lee, Virginia Olesen, Caroline Baer Rose, Ethel Shanas, Irene B. Taeuber, Rosalie Wax, and Hattie Plum Williams. 
were caught up in relationships of disadvantageous interdependency, including with the supervisors who were ostensibly advising their work and forwarding their careers. Ultimately - possible because of the prevailing system of professional placement - they were ostracized from the central network, and their names and their intellectual contributions thrust into obscurity.

Because of its close connections with both the present and absent women under scrutiny, the Chicago School of sociology serves as a special case, strikingly illustrative of the dynamics that connect the two knowledge-generating fields under examination, namely the canonical disciplinary histories and the newer hybrid digital space, exemplified in Wikipedia. Serious archival research, as practiced in the sourcebook and reader, can recover at least a part of the missing knowledge of academic disciplinary history. On Wikipedia, however, the article reference links that are provided, while readily accessible, are even more mediated and therefore less useful in identifying the gaps into which information may have fallen.

From its origin in 1892 until at least the 1960s, the sociology department at the University of Chicago powerfully influenced the development of the discipline. The Chicago School is one of only two schools - the other being the Wisconsin School - that have so far been widely and explicitly enshrined as such in the history of American sociology. Regardless of the diversified research orientations and methodologies prevalent within the circle, and despite other great departments that have also exerted a strong influence on the enterprise of American sociology (Tomasi 1998), the Chicago School was one that managed to brand itself. As such, the history of the Chicago School is typically narrated around critical thoughts and activities of its male contributors. Women scholars who were trained or taught there have either been ignored in the most-cited books on the School or have appeared among lists of names without deeper inquiry into their research. For instance, Robert E.L. Faris' 1979 recollection Chicago Sociology 1920-1932 lists eight male sociologists as the School's leading personalities. The same is true of Martin Bulmer's 1984 book The Chicago School of Sociology: Institutionalization, Diversity, and the Rise of Sociological Research, whose main focus is the scholarly contributions of fifteen founding fathers. Names such as Edith Abbott, Ruth Shonle Cavan, Helen MacGill Hughes, Harriet Mowrer, and Pauline Young do appear sporadically in the books. Sometimes the authors praise the women's contributions, even enthusiastically, although they never consider them important figures. ${ }^{23}$ Both

23 For instance, the two books describe Pauline Young's work Pilgrims of Russian Town (1932) as an exemplar of the earliest attempt of participant observation. Her research methods textbook was also acknowledged as influential in the Chicago sociological community 
Faris and Bulmer had stayed in the University of Chicago, so their narratives have had additional influence as insiders, serving as authoritative references for later works on the subject. ${ }^{24}$

What of the Wikipedia landscape and the Chicago School? A simple search of "the Chicago School of sociology" shows that Wikipedia basically replicates dominant narratives concerning the School. Although tremendously influential on the early development of the discipline, "the Chicago School (sociology)" Wikipedia entry is also tangential, and includes a total of 174 revisions by 117 editors, a relatively small size compared to similar topics in other fields. ${ }^{25}$ The representative scholars of the School are listed in the entry as follows:

The major researchers in the first Chicago School included Nels Anderson, Ernest Burgess, Ruth Shonle Cavan, Edward Franklin Frazier, Everett Hughes, Roderick D. McKenzie, George Herbert Mead, Robert E. Park, Walter C. Reckless, Edwin Sutherland, W.I. Thomas, Frederic Thrasher, Louis Wirth, Florian Znaniecki. Activist, social scientist and Nobel Peace Prize winner Jane Addams also forged and maintained close ties with some of the members of the Chicago School of Sociology. ${ }^{26}$

In this short paragraph, only two women are included: Ruth Shonle Cavan and Jane Addams. A prolific writer who received national recognition for her scholarly work in sociology and criminology, Cavan has only a one-sentence Wikipedia biography: "Ruth Shonle Cavan (August 28, 1896-August 25, 1993) was an early American sociologist."

The problem of vanished women in the history of the Chicago School has been acknowledged by a few authors, although they do not attempt to ameliorate it in their own writings. In his Evaluating Chicago Sociology: A Guide to the Literature, with an Annotated Bibliography (1984), Lester R. Kurtz notes that the role of women scholars in shaping the Chicago sociology department has been

(Faris [1979], p. 71; Bulmer [1984], p. 4, p.65). But Young was not considered an important representative of the school and her name cannot be found on Wikipedia. Similar situations characterize other female figures whose names were mentioned as important contributors without further information having been provided.

24 Citation counts on Google Scholar as of May 6, 2017 were 570 and 869 for Faris' and Bulmer's books respectively compared to 83 for Deegan's. When we updated the counts on February 26, 2018, Faris' book had been cited 632 times; Bulmer's 1009, and Deegan's 94. This particular gap is widening.

25 For instance, the Wikipedia entry for the Chicago school of economics was revised 630 times by 360 editors; page accessed on February 28, 2018.

26 See https://en.wikipedia.org/wiki/Chicago_school_(sociology). (accessed on February 28, 2018). 
underestimated (Kurtz 1984: 6). In addition to the Hull House contribution, he suggests that certain women who were positioned outside the traditional professorial track - e.g. lecturer, administrator, editor, graduate student, and faculty spouse - should also be included in the history of the sociological community. Yet Kurtz does not pursue his own call in the text.

In his canonical study of the Chicago department, Andrew Abbott also notes that existing literature on women of the Chicago School was minimal, with Deegan's work then virtually the entire corpus on the subject (Abbott 1999: 25). He argues that Deegan's emphasis on rediscovering the centrality of women in the Chicago School is an "emplotment" within the survey and reform tradition, sans serious engagement with the theoretical stance of the school. The School owes much to women social reformers and the related social survey movement, he contends, but they should not be considered a constituent part of the theoretical tradition. In Abbott's depiction of the department's early history, Helen MacGill Hughes appears to be the only woman who influenced the discipline in that regard, specifically because of the "interventionist" character of her editorship of the American Journal of Sociology.

At one level, Abbott's argument represents an established practice of history writing in academic disciplines: the construction of disciplinary history centered on concepts and theories. Intellectual credit is awarded to individuals and groups associated with theoretical breakthroughs, particularly those that have been collectively flagged and adopted. Contributions labeled 'empirical' or 'methodological' are deemed less significant in demarcating the core development of the discipline. Whether the labels are correct, or whether or not this is a reasonable approach at all, is worthy of further discussion. Many female and some male scholars have been marginalized in this fashion, in any case, their contributions written out of disciplinary history.

If the relationship between theory and empirical research in advancing sociological knowledge is a dialectical one, as Mark Gould (1990) has argued, an alternative approach is possible, one that would have distinctive implications for gendered inclusion. In this view, empirical research is not simply a testing ground to falsify a theory, in order to meet scientific standards when controlled experimental settings are not available. Empirical observations and fine descriptive details can clarify and modify concepts, generate new puzzles, and promote methodological innovations to meet immediate research needs. The multivalent term "paradigm", popularized by Thomas Kuhn's The Structure of Scientific Revolutions (1996), actually includes basic ideas, concepts, problematics, and findings. When paradigm shifts are placed at the center of disciplinary history, and the concept disaggregated and systematically reapplied, empirical research is likely to be reweighted in relationship to predominantly theoretical 
works. Of the missing women under scrutiny, Hattie Plum Williams, Lucile Evans, Ethel Shanas, Margaret Hagood, Frances Donavan, and Pauline V. Young all delivered excellent empirical studies and generated methodological innovations en route. Their works, still neglected in contemporary sociology, strove to achieve a balance among statistical reduction, empirical richness and theoretical depth.

Yet even that is too simple, for it ignores the people and processes that select out potential female theoretical contenders, and their active repression in sociological communities. Tracing back the history of the Chicago School along the analytical byways we earlier proposed, for example, we encounter a case of an 'erased' female sociologist whose experience illustrates one such process, that managed by powerful individuals within the academic enterprise who were able to play a gatekeeper role. Amy Hewes was the only woman between 1892 and 1920 who received a fellowship in the sociology department. Hewes' struggle began during her graduate studies, during which time Albion W. Small was serving as department chair. Her first publication in AJs, a brilliant piece titled "Seminar Notes: Social Interest and the Riemann Surface" (1899), was simultaneously solicited and dismissed by Small in a footnote featured on the first page of the article:

When the figure, JOURNAL of Sociology, November, 1898, p.382, was explained to the class of which the writer of this paper was a member, Miss Hewes suggested that the thought could be more fully indicated by the symbolism of the Riemann doctrine. She was requested to elaborate the suggestion, and the paper may accordingly be read as an appendix to the chapter above cited. As its two closing paragraphs clearly indicate, it is not an attempt to give final formulation to social combinations. It tries to make the fact of the complexity in all social reactions more evident, and to give an approximate notion of the degree of that complexity. Miss Hewes' contribution to the subject is certainly commendable.

A.W.S. ${ }^{27}$

The patronizing tone of the entry is unmistakable. Despite her demonstrated brilliance and the solidity of her academic record, Hewes was unable to secure an academic placement after completing her dissertation at Chicago. Small effectively sidelined her. Hewes wrote several letters to Small, urging that he support her academic job search, as was conventional at the time. She 
understandably declined the only job Small arranged for her as an instructor of German language in Florida. In a letter to Small, she wrote:

I want very much to teach ... in political science - civics, constitutional and diplomatic history, elementary economics and sociology - or something within hailing distance of these I should not hesitate - but German is a sight too wide of the mark.

DEEGAN 1991: 165

Despite these formidable obstacles, Hewes achieved a prolific career both within and beyond academia. She authored over forty publications in major academic journals, and five books, including the projects she directed for the Women's Educational and Industrial Union (WEIU). Yet ultimately Amy Hewes was barred from academic sociology, and her traces on the contemporary 'academic' internet are more sparse than they otherwise would have been.

Amy Hewes is not an idiosyncratic case. Another woman sociologist who is missing in action online, namely Mary Elizabeth Burroughs Roberts Smith Coolidge, encountered similar obstacles, heightened by her own department as the gatekeeper. According to Deegan (1991), Coolidge was the first American full-time professor in sociology, itself a fascinating status, and a statistician of women's poverty. She suffered a "mental collapse" - which bears further investigation - and resigned from Stanford for health reasons in 1903. The department of sociology refused to rehire her one year later, after her recovery. Coolidge accepted a position as the director of the San Francisco Settlement. She was unable to find an academic job in sociology for fifteen years, ultimately securing one in 1918, at a liberal arts college for women.

Another way that appeared to enable women to maintain their connections to intellectual life and community, while also downgrading the character of their work and contributions, was marriage. Typically, the members of an academic couple were initially on a similar academic track, although the female faced special obstacles posed by the discriminatory academic job market. Despite the attendant difficulties, exceptional women were able to assemble a successful career comparable to their spouses'. However, only the male sociologists were remembered for their contribution to the discipline, on Wikipedia and beyond. 
This point could be illustrated by multiple cases; here we detail just a few. The sociological couple of Alfred McClung Lee and Elizabeth Briant Lee ${ }^{28}$ attended the University of Pittsburgh, where each completed bachelor's and master's degrees. They then enrolled in Yale's doctoral program, with McClung Lee receiving his degree in sociology in 1933 and Briant Lee hers in 1937. After graduate school, however, Briant Lee faced more difficult conditions on the job market. Unlike McClung Lee, who then began his long career of university scholarship, Briant Lee could only land temporary and part-time teaching jobs. She accepted organizational tasks for professional associations including the Society for the Study of Social Problems; Association for Humanist Sociology; Sociological Practice Association, and the Eastern Sociological Society. In addition to various academic awards, she received the 1990 American Sociological Association Practice Distinguished Career Award for the Practice of Sociology together with McClung Lee.

The discrepant academic trajectory traversed by the couple is copied onto their online representation. The first three online search results for Alfred McClung Lee include a Wikipedia page, an introduction to him and his work on the American Sociological Association website, and his New York Times obituary. Elizabeth Briant Lee does not have her own Wikipedia page. If one searches for Briant Lee's name online, the first ten results are addresses that group the Lee couple together for their contribution to sociology. If one searches McClung Lee instead, only two of the first ten results mention Briant Lee as an academic in addition to having been McClung Lee's wife.

This argument differs from the supply-side argument that women must sacrifice their career for family. Rather, the point is that women's academic contributions were blended into spousal careers, particularly when they collaborated. A similar situation arose with Caroline Baer Rose and Arnold Marshall Rose, both first-rate sociologists. Baer Rose married Marshall Rose during her graduate studies in sociology at the University of Chicago, where Marshall Rose was a student four years her junior. The couple went on to several book projects, now misrecognized as Marshall Rose's solo works. Baer Rose also has numerous solo publications, including an influential $195^{\circ}$ article in the American Journal of Sociology (Deegan 1991: 335-341). Only after Marshall Rose's death was Baer Rose able to serve as a regular faculty member at the University of Minnesota sociology department, where she held temporary appointments for sixteen years. Searching Caroline Baer Rose online, the first result is Arnold

28 See Deegan (1991), pp. 249-255, for a more complete account of Elizabeth Briant Lee's life and career. 
Marshall Rose's Wikipedia page, where Baer Rose is mentioned as such: "Rose married sociologist and professor Caroline Baer in 1943." The second result is a link to an introduction of Marshall Rose on the ASA website, where Baer Rose appears twice (with, at this writing, her name incorrectly spelled):29

His Presidential address was read at the 1969 Annual Meeting by his wife, Caroline Rose.

In 1967, Rose and his wife, Caroline Bauer [sic] Rose, a sociologist who collaborated with him on some of his work, donated $\$ 200,000$ to the American Sociological Association to establish the Arnold and Caroline Rose Fund.

In the above cases, the wife is absent from both academic history and from Wikipedia. The third case, the Hughes couple of the Chicago school, represents a different scenario, in which the wife is depicted in the disciplinary history as a helping hand to her husband and is downgraded on Wikipedia. In the Wikipedia page for the sociologist Everett C. Hughes, his wife Helen McGill Hughes, who does not have a page of her own, is mentioned as follows:

He was married to Canadian sociologist Helen McGill Hughes, whom he met when they had both been $\mathrm{PhD}$ students in Chicago. They had two daughters. In addition to some independent research, Helen McGill Hughes took part in several of Hughes's studies and also worked as managing editor for American Journal of Sociology from 1944 to 1961.

Аввотт $1999^{30}$

It is worth noting that the above Wikipedia text cites Andrew Abbott's Department and Discipline: Chicago Sociology at One Hundred (1999) as a reference. The Wikipedia text, however, does not simply reduce but also distorts its source. According to Abbott, Helen McGill Hughes was the de facto editor of AJS from 1944 to 1961 (Abbott 1999: 82) and transformed the AJs editorial structure during her service. She instituted formal editorial board meetings, and did extensive copyediting, such that some of her policies were criticized by her University of Chicago colleagues as "interventionist editing" (ibid, 16o).

29 See http://www.asanet.org/about/presidents/Arnold_Rose.cfm (accessed on February 28, 2018).

30 See https://en.wikipedia.org/wiki/Everett_Hughes_(sociologist). (accessed on February $28,2018)$. 
In the sourcebook, Helen McGill Hughes' specific scholarly achievements are mentioned in addition to her AJs editorship. Her research ranged from popular culture and mass communication to women's work in sociology (Deegan 1991: 194-196). Note, however, that both her sociological studies and her influence over one of the discipline-shaping journals of sociology are obliterated from the online domain. Even when Wikipedia contributors consult canonical disciplinary histories, and women's contributions are reflected there, truncated selection and misreading may well intervene.

When the members of early U.S. academic couples do have a Wikipedia entry of their own, they tend to be of sharply different quality. Witness the cases of Dorothy Swaine Thomas and W.I. Thomas, and Helen Merrell Lynd and Robert S. Lynd. The immediate impression of the associated Wikipedia pages is that the women's pages are substantially shorter and less curated than those of their spouses. Swaine Thomas' page has 8 total revisions from 5 editors, while her husband Thomas' entry has been revised 174 times by 87 editors; Merrell Lynd has 47 revisions by 33 editors, compared to Lynd who himself has 70 revisions from 48 editors. ${ }^{31}$ In general, men's pages attracted more contributors than women's pages.

Dorothy Swaine Thomas was the first female president of the American Sociological Society. ${ }^{32}$ Her numerous academic achievements, although truncated, are recorded in the Wikipedia entry. When comparing Swaine Thomas's entry with the page for her husband W.I. Thomas, however, it becomes evident that the major feature distinguishing the two pages is not the list of facts per $s e$, but how the individual is portrayed in relation to the broader discipline and its expanding stock of knowledge. Despite the institutional names with which she was affiliated, and several keywords summarizing her research interests, we gain only scanty information about Swaine Thomas' intellectual life from her online page. In contrast, we learn much more about the intellectual lineage

31 See https://en.wikipedia.org/wiki/Dorothy_Swaine_Thomas and https://en.wikipedia .org/wiki/W._I._Thomas. Pages accessed on February 28, 2018.

32 See Deegan (1991), pp. 400-408. Dorothy Swaine Thomas majored in economics and sociology at Barnard and received her doctorate from LSE. Swaine Thomas completed her dissertation in two years, and it was immediately accepted for publication. With a postdoctoral fellowship from the Social Science Research Council (SSRC), she collaborated with her future husband W.I. Thomas on the influential book The Child in America (1928). She served in faculty and research positions in several top universities and was tenured at UC Berkeley. Mastering both quantitative and qualitative research skills, Swaine Thomas published in a wide range of topics including observational studies of social interaction; the Japanese-American internment of wWII, and population and economic growth. Besides the leading ASA honorific position, she was also the first female board member of the SSRC and was later its director. 
of W.I. Thomas' thoughts from his Wikipedia entry: from whence his thoughts originated; how they developed over the course of his academic career, and where they are positioned in the larger field of sociological knowledge.

The last point is especially crucial because the way in which his ideas are presented in relation to his professional peers' implies that he was considered as part of an intellectual community rather than as a network isolate. According to Wikipedia, William Thomas belonged to "a group often referred to as the earlier psychological school of sociologists along with Franklin Henry Giddings, E.A. Ross, Charles Cooley, and Ellsworth Faris"; ${ }^{33}$ his research interests were influenced by "the historical and methodological approach of Professor Small and the remedial and correctional interests of Professor Henderson"; two paragraphs introduce his research on migration and the Polish peasant, together with a section devoted to the contentious debates arising around his analysis of the Polish community in the United States; his subsequent arrest by the FBI; and the reaction of the University of Chicago sociology department. In short, W.I. Thomas' Wikipedia page testifies to his embeddedness within the sociological community, in contrast to Dorothy Swaine Thomas' entry, which disproportionately reflects an image of derived membership via her husband.

In reality, the 'missing' women were quite connected to other prominent figures in the intellectual community. At the University of Chicago, Herbert Blumer, Louis Wirth, Helen Hughes and Everett Hughes were classmates and close friends from graduate school onwards (Abbott 1999:117); yet on Wikipedia, only Helen Hughes is absent. And what is perhaps most fascinating, the missing scholars themselves also share longstanding relationships, whether of friendship, mutual mentorship, or fellow-feeling. Ethel Shanas worked together with Helen Hughes as graduate student assistants for AJS (ibid, 119); Lucile Eaves and Mary Roberts Coolidge studied together at Stanford under E.A. Ross (Eaves 1928[2000]); Eaves talked to Coolidge about her study of Chinese immigrants (1909) and discussed it intensely in her own work on California labor movements (Eaves 1910: 3); Eaves mentored Hattie Plum Williams who later served as the department chair of political science and sociology at University of Nebraska; Rosalie Wax worked for Dorothy Swaine Thomas in conducting an ethnography of Japanese evacuees, etc. The shared personal connections of the 'forgotten females' suggest their embeddedness within the ongoing project of institutionalized American sociology. Systematic erasure of a woman's embeddedness in the greater intellectual community and connectedness to her fellow scholars in the digital representation contributes to the women's 
collective absence. In Orlando Patterson's eloquent phrase, it is a kind of "social death" (Patterson 1982).

\section{The Depersonalized Representation of Key Organizations}

The fact that these women were collectively forgotten is also related to the misrepresentation of critical organizations with which they were actively involved. As the dominant institution in the early development of American sociology, the University of Chicago's influence has extended over the organization and location itself. In the following sections, we trace the connections of females affiliated with the school to other institutions to identify key mechanisms related to the representation of organization that figure in the women's absence.

The Women's Educational and Industrial Union (WEIU) is an excellent example of how the history of sociology neglects important sociological work in institutional settings outside of academia. More importantly for our purposes, the WEIU case illustrates how critical women sociologists are absent from the mainstream narrative of the discipline represented by canonical disciplinary histories and from digital platforms like Wikipedia. Tracing the processes of knowledge formation, these two interacting spaces of knowledge generation actually entail different mechanisms that exclude critical women.

WEIU looms large in the biographies of several of our missing women: sociologists Annie Marion MacLean, Amy Hewes, Susan Kingsbury, and Lucile Eaves built their careers outside academia working for this organization. Of these notable scholars and professionals, only MacLean has a Wikipedia entry. WEIU has a Wikipedia page, listed under the WikiProject Women's History. ${ }^{34}$ The page includes the historical background of the establishment of WEIU, the original proposals of its founder Harriet Clisby (one of the first female physicians in the U.S., who herself did not have a Wikipedia entry at the writing of this paper), and a chronologically ordered list of events in which the organization participated from 1877 to 2004. The history of the organization is displayed as a series of developments and innovations initiated by the organization, rather than by any individual person as agent. ${ }^{35}$ Not surprisingly,

34 See https://en.wikipedia.org/wiki/Women\%27s_Educational_and_Industrial_Union (accessed on February 26, 2018).

35 Except in one record from 1899, the page informs us that Mary Morton Kehew, the president of WEIU, invited Helen Keller to speak to the Boston General Court about the importance of education for the blind. 
the Wikipedia page mentions none of the above female sociologists, certainly not in their roles as supervisors or directors of the organization's research department.

With the support of the WEIU research department, several notable female sociologists collaborated on a series of social inquiries into women's and children's working conditions in the early twentieth century. The organization also collaborated with other professional associations, including the American Sociological Society, to launch large-scale social investigations of "subjects of peculiar interest" such as self-supporting women (Eaves 1920). One of the influential projects from the WEIU department of research was the nine-volume Studies in Economic Relations of Women on women's working conditions in Massachusetts, published between 1911 and $1916 .{ }^{36}$ Major contributors to the study, including Susan M. Kingsbury, Marion Parris Smith, Amy Hewes, May Allinson, and Lila Ver Planck North, all of whom are absent on Wikipedia, have significant publication records and held leading positions at universities as sociologists or economists. A few of them, such as Allinson and North, have virtually vanished in the public domain, so much so that there seem to remain no publicly accessible sources of biographical information except their names and the titles of their publications.

The relation between these female scholars and mainstream academia at the time is implied in the reception of this intensive research project Economic Relations. The work was reviewed by several top academic journals including the Journal of Education (JE) (1912, 1914, 1916, 1918), the Journal of Political Economy (JPE) (1916), the American Journal of Sociology (AJS) (1916), and the American Economic Review (AER) (1914). The reviews were strikingly different. The Journal of Education and AER praised WEIU as one of "the most reliable, efficient, conscientiously managed institutions of a semi-philanthropic educational industrial nature in the country." 37 The editors highly recommended WEIU's research on the impact of economic conditions on women and complimented the rigorous research design. ${ }^{38}$ In contrast, the review published by

36 Volume I, II, IV, VI were prepared under the direction of Susan M. Kingsbury, volume III edited by Foy Spenser Baldwin, volume v coedited by Susan M. Kingsbury and Marion Parris Smith, volume viI under the direction of Amy Hewes, volume viII under the direction of May Allinson, volume IX co-directed by Susan M. Kingsbury and May Allinson. Reviewed Work: Millinery as a Trade for Women by Lorinda Perry, Susan Myra Kingsbury, Marion Parris Smith, Review by: The Journal of Education Vol. 84, No. 23 (December 21, 1916), p. 638.

38 Reviewed Work: Industrial Home Work in Massachusetts, Review by: Sarah S.W. Walden, The American Economic Review, Vol. 6, No. 2 (Jun., 1916), pp. 400-403. 
AJS was harsh, and explicitly directed at Amy Hewes, the director of this research, characterizing her study as "repetitive and tedious":

It is surprising that from a painstaking, carefully arranged report, with a preface containing an admirable summary, the total impression is confusing. Facts stand out clearly enough, but their meaning is obscure ... from the conclusions one is honestly forced to the impression of much ado about little. ${ }^{39}$

It is worth noting the dual gatekeeping mechanism that contributed to Amy Hewes' absence in the history of American sociology. As we have discussed, Hewes was first patronized and then professionally sidelined by Albion Small, a powerful individual in the discipline, and could not independently secure an academic job at prestigious sociology departments. After she found her voice in nontraditional academic settings, Hewes' work was specifically downgraded by Chicago's AJs, the discipline's flagship journal.

The negative reception of WEIU in mainline sociology at the time also contributed to the later obscurity of its female contributors in the history of the discipline. ${ }^{40}$ Nonetheless, materials on the organization from non-Wikipedia sources do contain some information on the women sociologists, even if the quality is relatively poor. Why, then, did these female names disappear completely from the Wikipedia article on WEIU? How was the organizational history so utterly depersonalized?

The Wikipedia page on WEIU had been revised 25 times by 15 editors at the time of this paper's writing. ${ }^{41}$ We find that editors select the organization as the main actor to construct a history detailed via bullet-point events; at the same time, the editors systematically jettison information on relevant female actors. The content of the article is assembled mainly based on an online introduction of the organization from Harvard University Library Open Collections

39 Reviewed Work: Industrial Home Work in Massachusetts. by Department of Research, Women's Educational and Industrial Union, Massachusetts Bureau of Statistics, Amy Hewes, Review by: Ordway Tead, American Journal of Sociology, Vol. 21, No. 5 (Mar., 1916), pp. 701-702.

40 Another noteworthy study, Aged Clients of Boston Social Agencies (1925), under the direction of another forgotten sociologist Lucile Eaves, also received contrasting reviews from AJS and JPE. The review from the Chicago trained sociologist Stuart A. Queen at AJS was cursory and unappreciative in comparison to AER's by J.P. Chamberlain, who praised Eaves and declared she should "be congratulated on the product of her 'cooperative social research.'"

41 See https://en.wikipedia.org/wiki/Women\%27s_Educational_and_Industrial_Union. Page accessed on February 26, 2018. 
Program ${ }^{42}$ and a paper published on the Historical Journal of Massachusetts by professor Erica L. Harth of Women's, Gender and Sexuality Studies. ${ }^{43}$ The Harvard article is a brief introduction to their archival collection. Despite a one-sentence introduction to the founder of WEIU at the outset of the document, the page does not mention a single individual who worked for the organization. Harth's article, on the other hand, is an informative piece on the early development of WEIU, with rich details on several remarkable women leaders. Yet the names of these female scholars - including some who are also absent from the sourcebook, such as May Allinson - disappeared when the article was quoted in the Wikipedia entry.

Merging critical actors into larger organizational settings is a general way of writing institutional history, not just a feature of representations of womendriven organizations. This common historiographical practice is a particular problem in this regard, however, since writing the history of such organizations constitutes one of the few avenues to surface important contributions of women scholars otherwise barred from organizational participation and deleted from memory. The Wikipedia representation of WEIU crystallizes yet another route by which critical institutions of women sociologists become marginalized in the history of the profession. And it is a double whammy, as it were: WEIU's welfare policy-oriented work first fails to be recognized by the discipline and is therefore gradually swept under the rug. Yet when a scholar uncovers these women's accomplishments and reconstructs a history of the organization, the names of the women and their contributions are re-submerged, and their efforts and accomplishments repressed, and not conveyed to Wikipedia readers.

The Survivors? (Mis)remembered Women Scholars

Information quality and reliability is an enormous concern for supporters and critics of crowd-sourced materials. Collaborative technology is believed to promote information accuracy by allowing relatively easy discovery and correction of errors with an enormous user base, at least in the case of sciencerelated entries (Giles 2005). The open discussion of quality issues featured in

42 See http://ocp.hul.harvard.edu/ww/weiu.html (accessed on February 26, 2018).

43 Harth, Erica. 1999. Founding Mothers of Social Justice. One source appeared in the footnote of the Wiki page is "Women's Educational and Industrial Union. A Brief History of the Women's Union. Women's Educational and Industrial Union, 2005". Similar content from this source has been repeatedly quoted in a number of online articles introducing WEIU, but the actual source could not be located in any online and offline library catalogs. 
the Wikipedia collaborative architecture, coupled with efficient systemic responses to these discussions, would be expected to guarantee that the quality of crowd-generated knowledge might be better than would otherwise be expected (Stvilia et al. 2008). There are a lot of "woulds" and "should" there, to be sure. To discover whether this optimistic and quasi-normative prospect is accurate, we analyze the discussion sections attached to each entry: the "Talk" page. According to the Wikipedia's user guide, a Talk page is "a page which editors can use to discuss improvements to an article or other Wikipedia page."44 It usually contains several key issues on which the editors disagree and that are reflected in the editing history of the entry. The page also indicates the WikiProjects to which the current entry is attached. WikiProject is a collective effort by participants who wish to work together on the same topical subject, such as "Women's History". Articles attached to WikiProjects receive a quality rating according to an assessment scale introduced by the English Wikipedia in $2007 .^{45}$

Twenty-six of the $37(70 \%)$ women from the sourcebook who have their own Wikipedia entries are included in one or multiple WikiProjects, the most common topics ranging from "Women Scientists", "Women's History", "Science and Academia", to the more generic ones such as "Biography" and "Politics". The quality rating is divided into two parts: a "quality" class and an "importance" class. Sixteen $(31 \%)$ articles are not assessed for their quality and more than half of the entries for female sociologists do not receive a rating on the importance scale. Twenty-one (41\%) articles are rated Stub and Start quality, which typically contains a paragraph summarizing the scholar's positions, a short biography, and a list of her major publications.

An entry for Elsie Clews Parsons is representative of articles receiving the Stub/Start rating on the quality scale. ${ }^{46}$ Comparing the entry with the relevant article in the sourcebook, the major difference is not only the articles' length, but also their emphasis. The Wikipedia entry lays out Parsons' areas of research and her positions in professional organizations. Yet we do not learn much about her as a scholar: her thinking; her standing in the field of sociology; the critiques she received from academic peers, and other issues related to Parsons' professional identity as an academic. The narrative of Parsons' life in the Wikipedia entry is compiled by means of the activities of her male family

44 See https://en.wikipedia.org/wiki/Help:Using_talk_pages (accessed on February 28, 2018).

45 On the WikiProjects, see: https://en.wikipedia.org/wiki/WikiProject\#cite_note-Deng-5 and https://en.wikipedia.org/wiki/Wikipedia:WikiProject (accessed on February 26, 2018).

46 https://en.wikipedia.org/wiki/Elsie_Clews_Parsons (accessed on February 28, 2018). 
members: her wealthy banker father, her artist brother, and her congressman husband. The sourcebook article, on the other hand, highlights Parsons' intellectual transition from a sociologist to an anthropologist, her commitment and contribution to feminist theory, and her contributions to the discipline of sociology.

The 'unassessed' ones are of even poorer quality, containing little useful and sometimes completely incorrect information. Helena Znaniecka Lopata's Wikipedia entry, for example, accessed at press-time, fails to capture her sociological contributions ... and spells her name wrong. Comparing the overlapping entries in both reference texts reveals a disappointing landscape for the even basic representation of female sociologists on Wikipedia.

Perhaps the most interesting case is the brilliant Ida B. Wells (2016), mentioned above, whose complex intellectual and political career traces a pathway to the complexity of intersectionality (McCall 2005), now translated into the contemporary digital sphere. Technically Wells belongs to the 'remembered' category of our fourfold table. Her Wikipedia page is of comparatively high quality, and the associated Wikipedia Talk page contains heated debates on both the racially- and gendered-tilted contents of various editions of the entry. Unlike most Wikipedia entries, however, Wells' is also sophisticated and evenhanded enough to refer to her academic and public work having been both recognized historically and sidelined by both white and black male intellectuals. Ironically, Ida B. Wells' Wikipedia entry - at least at this writing, for entries can and do change - has become a kind of model for the potential improvement of other academic women's Wikipedia entries.

\section{9 Conclusion and Discussion}

To understand why some rather than other notable women are missing from the disciplinary history of American sociology, this study analyzes the problematic gender representation of women sociologists in an emerging textual interactional space. Exploring the relationship between canonical history and the most important online platform, Wikipedia, we outlined four possible situations - remembered; neglected; erased; or recovered - in which women scholars are represented in the process of knowledge generation both online and in print. Guided by these four conceptual categories, we further scrutinize women's trajectories during the early development of the discipline; the negative impact that the fact of their marriages had on the perception and representation of women scholars; the buried depersonalized history of critical 
women's organizations, and the systematic misrepresentation of women who do have online presence.

Women scholars are selectively underrepresented and misrepresented in the new digital repertoire, we find, as a combined consequence of the defects entrenched in the older print histories and the inherent drawbacks of the new online sphere. First, as our investigation confirms, Deegan's sourcebook accurately assesses the negative consequences that emerged from the early exclusion of female scholars from professional positions in American sociology. Yet there are special twists to the process of disappearance, we find, beginning with the emergence of the discipline and profession, which have persisted robustly to the present and are now rapidly diffusing into the online domain. Wikipedia's hybrid crowdsourced model cannot mitigate the main thrust of the process of selective neglect, for example, because Wikipedia's notability standards encourage the replication of the flawed and incomplete information that is already established.

Second, more empirically-driven or case-based research, and academic work that is conducted outside academic institutions - in sites where the early women sociologists were perforce concentrated - are more likely to be ignored in disciplinary histories. This patterned underrepresentation has negative consequences for women's presence not only in the history of sociology - for example the Chicago School - but also in the contemporary sociological community. ${ }^{47}$ This is not the only problematic mechanism, but to the extent that the academy continues to underplay the earlier sociological tradition including empirical study and methodological innovations in favor of the tradition of theory-building that has heretofore dominated the writing of disciplinary history, the problem of many women's absence in the history of sociology will be difficult to solve. ${ }^{48}$ Yet the powerful - and in some cases implacable - internal resistance to the work of women theorists such as Amy Hewes shows that it is not simply an issue of the difference between more conventionally-coded theoretical and empirical foci. As we have discussed in the case of the Chicago

47 For instance, research shows that women sociologists are underrepresented in top-tier academic journals, composing only $28 \%$ of all authors in AJS and ASR (Karides et al. 2001).

48 Note that the underrepresentation of women in publishing continues to be patterned along subfields that correspond to what is now a historically resilient gender division of labor: female sociologists are still more likely than men to publish empirical, evidencebased articles, and on topics such as women, children, immigration, poverty, and advocacy, while male sociologists are more likely to produce theoretical and conceptual articles (Grant et al. 2002). 
school and WEIU, a multiple-gatekeeping mechanism disciplined women out of the theoretical space and canonical history.

Third, women in academia are more likely to be forgotten not only because of their subordinate position in the male-dominated intellectual enterprise, but also because a goodly number have sacrificed professional lives for their husbands' careers and mobility. This contributes to the eminent women's relative obscurity, which cannot be compensated for by the open-source knowledge production on Wikipedia and its ilk. While both genders were often on the same track towards a mature academic career, as our analyses show, the intellectual community eventually marginalized the female sociologists and/ or contributed to their decisions to subordinate their talents in support of their husbands. Despite these personal and institutional barriers, many early female sociologists effectively pieced together a career outside academia, but unlike the male leaders who secured positions that then led to their figuration as key organizational actors, women's contributions have disproportionately merged into the legacies of the organizations they served. The multiple strands of underrepresentation of women in academia have resulted in historical underdocumentation of women sociologists on Wikipedia.

Finally, Wikipedia's overemphasis on secondary sources as an indicator of the subject's significance also impedes the unbiased representation of women. An inherent disadvantage of Wikipedia's mode of creating knowledge is the network centralization of human resources. The more well-documented an individual or a topic, the more editors gravitate to it, while the quality of entries for less central people or topics is largely contingent upon a single contributor's expertise. In the case of the WEIU Wikipedia entry, the editors' heavy reliance on other online sources unmediated by critical reflection has perpetuated the drawbacks of existing sources. Still more problematic is their summary of the more comprehensive peer-review article. Wikipedia editors have reduced the history of the organization to a list of events initiated in the name of the organization, effacing the contributions of actors. As a result, this key organization enters the Wikipedia space, but the women who foundationally contributed to its development do not.

When exploring the lives of the missing sociologists, we also registered a century-long legacy of women scholars' endeavoring to reinstate other missing women whom they believed deserved more recognition. Examples include Anne Firor Scott's rediscovery of Margaret Jarman Hagood's study of southern women in the 1930s; Ruth Benedict's promotion of Mary Wollstonecraft; Ruth Shonle Cavan's reintroduction of Pauline V. Young, and many other contemporary initiatives. Barbara Celarent, née Andrew Abbott, is another intriguing 
recent addition. This particular pattern of agency relationships, of "action on behalf of" (Adams 2011), continues to this day; it deserves wider exploration.

Focusing on the case of American academic sociology, the mechanisms uncovered in this study that contributed to women's presence or absence in the new hybrid field of knowledge production open up several potential avenues of comparative research. First, more than 80 percent of Wikipedia's content is written in languages other than English (Fichman \& Hara 2014). The social, political, and cultural backgrounds of contributors and readers vary across different language versions of Wikipedia, which although structured by English language Wikipedia's early and continuing predominance, might also display divergent pathways of generating knowledge with regard to women scholars. Second, as we discussed at the outset of this paper, sociology, including U.S. sociology, exhibits some real national and disciplinary specificities. We may well observe distinctive forms of gatekeeping that hindered the diffusion of women's scholarship in both digital and print formats across academic disciplines and in different countries or regions. Note however that the four analytical categories proposed in this paper can be readily applied across and adjusted to different cultural and institutional contexts to capture the unique processes of women's digitally-mediated canonical representation. Finally, our genealogical perspective also enables further comparison of tranches of knowledge stocks across pre-digital and digital eras. Given the explosive technological advances of recent years, the processual view adopted in this study is necessary to understand the evolving sequence of formations of expert and crowd-sourced academic knowledge.

Although the current textual interactional space of traditional disciplinary history and new digital memory is largely unidirectional - that is, knowledge is transferred from canonical histories to the online sphere - this emergent space is changing. For example, the Wikimedia Foundation's ongoing efforts to counteract some of the organizational failures of the online encyclopedia; Wikipedia's own technical requirements, which are still relatively accessible, and its potentially collaborative environment may still model a positive shift in the way in which academic history is written. We have witnessed increasing attempts to write notable women back into history via Wikipedia, ${ }^{49}$ including

49 Examples of attempts to recover missing information on significant women on Wikipedia: 1) http://www.newyorker.com/tech/elements/a-feminist-edit-a-thon-seeksto-reshape-wikipedia; 2) https://boundary2.org/2016/03/og/wikipedia-woman-problem/; 3) http://www.smithsonianmag.com/smart-news/how-college-student-led-wikiprojectwomen-scientists-180958423/?no-ist. 
by evading some of its less constructive orientations toward primary source research. How the emergent digital knowledge repertoire might actually enrich disciplinary memory and academic knowledge is very much a live question. Perhaps, following Joan Acker (1973: 936), we might finally construct a sociology that does not "deal with only the male half of humanity," one in which the ladies aren't 'vanished'. That depends, however, on the thoughtful participation of disciplinary experts in the online digital space, and on a deeper, more accurate and less biased representation of the history of academic knowledge, including the participation of women scholars in American sociology and beyond.

\section{Acknowledgments}

The authors gratefully acknowledge support for this research from the National Science Foundation (grant $\#_{1322971)}$, research assistance from Yasmin Kakar, and comments from Scott Boorman, anonymous reviewers, participants in the Comparative Research Workshop at Yale Sociology, as well as from panelists and audience members at the Social Science History Association.

\section{References}

Abbott, Andrew. 1999. Department and Discipline: Chicago Sociology at One Hundred. Chicago, IL: University of Chicago Press.

Acker, Joan. 1973. "Women in Social Stratification: A Case of Intellectual Sexism," American Journal of Sociology 78 (4): 936-945.

Adams, Bert N., and R.A. Sydie. 2001. Sociological Theory. Thousand Oaks, CA: Pine Forge Press.

Adams, Julia. 2011. "1-80o-How-Am-I-Driving? Agency in Social Science History," Social Science History 35 (1): 1-17.

Adams, Julia, and Hannah Brueckner. 2015. "Wikipedia, Sociology, and the Promise and Pitfalls of Big Data." Big Data \& Society 2 (2): 1-5.

Adams, Julia, Elisabeth S. Clemens and Ann Shola Orloff. 2005. "Social Theory, Modernity, and the Three Waves of Historical Sociology." Pp. 1-76 in Remaking Modernity: Politics, History and Sociology, edited by J. Adams, E.S. Clemens and A.S. Orloff. Chapel Hill, NC: Duke University Press.

Black, Erick W. 2008. "Wikipedia and Academic Peer Review:Wikipedia as a Recognized Medium for Scholarly Publication?” Online Information Review 32 (1): 73-88. 
Bourdieu, Pierre. 1984. Distinction: A Social Critique of the Judgement of Taste. Cambridge, MA: Harvard University Press.

Broschart, Kay Richards. 2008. "Teaching and Learning About Harriet Martineau and Other Women Founders of Sociology: I." Sociological Origins 5 (2): 15.

Bulmer, Martin. 1984. The Chicago School of Sociology: Institutionalization, Diversity, and the Rise of Sociological Research. Chicago, IL: University of Chicago Press.

Burke, Peter. 2012. A Social History of Knowledge II:From the Encyclopaedia to Wikipedia. Malden, MA: Polity Press.

Cavan, Ruth Shonle. 1983. "The Chicago School of Sociology, 1918-1933." Urban Life 11 (4): 407-420.

Celarent, Barbara. 2009. "The Woman Who Waits. By Frances Donovan. Boston: Richard G. Badger, 1919. Pp. 228. The Saleslady. By Frances Donovan. Chicago: University of Chicago Press, 1929. Pp. 267. The Schoolma'am. By Frances Donovan. New York: Frederick A. Stokes." American Journal of Sociology 115 (3): 984-99o.

Celarent, Barbara, and Andrew Abbott (ed.). 2017. Varieties of Social Imagination. Chicago, IL: University of Chicago Press.

Connell, Raewyn W. 1997. "Why is Classical Theory Classical?" American Journal of Sociology 102 (6): 1511-1557.

Coolidge, Mary Roberts. 1909. Chinese Immigration. New York, NY: Henry Holt and Company.

Deegan, Mary Jo. 1991. Women in Sociology: A Bio-bibliographical Sourcebook. Westport, CT: Greenwood Press.

Deegan, Mary Jo. 1995. "The Second Sex and the Chicago School, Women's Accounts, Knowledge, and Work, 1945-196o." Pp. 322-64 in A Second Chicago School?, edited by Gary A. Fine. Chicago, IL: University of Chicago Press.

Deegan, Mary Jo. 2002. Race, Hull-House, and the University of Chicago. Westport, CT: Praeger.

Deegan, Mary Jo. 2014. Annie Marion MacLean and the Chicago Schools of Sociology, 1894-1934. New Brunswick, NJ: Transaction Publishers.

Eaves, Lucile. 1910. A History of California Labor Legislation: With an Introductory Sketch of the San Francisco Labor Movement. Berkeley, CA: University of California Press.

Eaves, Lucile. 1920. "Plans for Co-Operative Research." American Journal of Sociology $25(5): 568-571$.

Eaves, Lucile. 1928[2000]. "My Sociological Life History." Sociological Origins 2 (2): 65-70.

Faris, Robert E. Lee. 1979. Chicago Sociology: 1920-1932. Chicago, IL: University of Chicago Press.

Feagin, Joe R. 2001. "Social Justice and Sociology: Agendas for the Twenty-First Century: Presidential Address." American Sociological Review 66 (1): 1-20. 
Feagin, Joe R., Hernan Vera and Kimberley Ducey. 2016. Liberation Sociology, 3rd Ed. New York, NY: Routledge.

Fichman, Pnina, \& Noriko Hara (ed.). 2014. Global Wikipedia: International and Crosscultural Issues in Online Collaboration. Rowman \& Littlefield.

Giles, Jim. 2005. “Internet Encyclopaedias Go Head to Head." Nature 438 (7070): 900-901. Gordon, Linda. 1992. "Social Insurance and Public Assistance: The Influence of Gender in Welfare Thought in the United States, 1890-1935." The American Historical Review 97 (1): 19-54.

Gould, Mark. 1990. "The Interplay of General Sociological Theory and Empirical Research." Pp. 399-416 in Robert K. Merton: Consensus and Controversy edited by Jon Clark, Celia Modgil, Sohan Modgil. New York, NY: Falmer Press.

Grant, Linda, Marybeth C. Stalp, and Kathryn B. Ward. 2002. "Women's Sociological Research and Writing in the "AJs" in the Pre-World War II Era." The American Sociologist 33 (3): 69-91.

Harth, Erica. 1999. "Founding Mothers of Social Justice: The Women's Educational and Industrial Union of Boston, 1877-1892." Historical Journal of Massachusetts 27 (2).

Hewes, Amy. 1899. "Seminar Notes: Social Interest and the Riemann Surface." American Journal of Sociology 5 (3): 392-403.

Hill, Michael R., and Susan Hoecker-Drysdale, eds. 2003. Harriet Martineau: Theoretical and Methodological Perspectives, with an Introduction by Helena Znanecka Lopata. New York: Routledge.

Hoecker-Drysdale, Susan. 1990. "Women Sociologists in Canada: The Careers of Helen MacGill Hughes, Aileen Dansken Ross, and Jean Robertson Burnet." Pp. 152-76 in Despite the Odds, edited by Marianne Gosztonyi Ainley. Montreal, CA: Vehicule Press.

Hoecker-Drysdale, Susan. 2008. "Teaching and Learning About Harriet Martineau and Other Women Founders of Sociology: II." Sociological Origins 5 (2): 16-17.

Howe, Jeff. 2008. Crowdsourcing: Why the Power of the Crowd is Driving the Future of Business. New York, NY: Crown Publishing.

Jackson, Robert Max. 200o. Destined for Equality: The Inevitable Rise of Women's Status. Cambridge, MA: Harvard University Press.

Karides, Marina, Joya Misra, Ivy Kennelly, and Stephanie Moller. 2001. "Representing the Discipline: Social Problems Compared to ASR and AJs." Social Problems 48 (1): 111-128.

Kuhn, Thomas. 1996. The Structure of Scientific Revolutions, 3rd Ed. Chicago, IL: University of Chicago Press.

Kurent, Heather Paul. 1982. Frances R. Donovan and the Chicago School of Sociology: A Case Study in Marginality (Doctoral Dissertation). Retrieved from University of Maryland Archives LD3231.M7od. 
Kurtz, Lester R. 1984. Evaluating Chicago Sociology: A Guide to the Literature. Chicago, IL: University of Chicago Press.

Lengermann, Patricia Madoo, and Gillian Niebrugge. 2007. The Women Founders: Sociology and Social Theory 1830-1930, A Text/Reader. Long Grove, IL: Waveland Press.

McCall, Leslie. 2005. "The Complexity of Intersectionality." SIGNS 30 (3):1771-1800.

McDonald, Lynn. 1995. The Early Origins of the Social Sciences. Montreal: McGillQueen's Press.

McDonald, Lynn. 1998. Women Theorists on Society and Politics. Waterloo, Canada: Wilfred Laurier University Press.

Merton, Robert K. "The Matthew Effect in Science." Pp. 439-459 in The Sociology of Science: Theoretical and Empirical Investigations, edited by Norman W. Store. Chicago, IL: The University of Chicago Press.

National Research Council. 1978. Century of Doctorates: Data Analyses of Growth and Change: U.S. PhD's - Their Numbers, Origins, Characteristics, and the Institutions From Which They Come: A Report to the National Science Foundation, to the National Endowment for the Humanities, and to. Washington, DC: The National Academies Press. Retrieved from https://www.nap.edu/catalog/18650/ century-of-doctorates-data-analyses-of-growth-and-change-us.

Parsons, Talcott. 1937. The Structure of Social Action: A Study in Social Theory with Special Reference to a Group of Recent European Writers. New York, NY: The Free Press.

Patterson, Orlando. 1982. Slavery and Social Death. Cambridge, MA: Harvard University Press.

Shils, Edward. 2006. A Fragment of Sociological Autobiography: The History of My Pursuit of A Few Ideas. New Brunswick, NJ: Transaction Publishers.

Sklar, Kathryn Kish. 1995. Florence Kelley and the Nation's Work. New Haven, CT: Yale University Press.

Stvilia, Besiki, Michael B. Twidale, Linda C. Smith, and Les Gasser. 2008. "Information Quality Work Organization in Wikipedia." Journal of the American Society for Information Science and Technology 59 (6): 983-1001.

Terry, James L. 1983. "Bringing Women ... In: A Modest Proposal." Teaching Sociology 10 (2): 251-261.

Thomas, Jan E. (eds.). 2005. Incorporating the Women Founders into Classical Theory Courses: A Resource Book. Washington, DC: American Sociological Association.

Thomas, Jan E., and Annis Kukulan. 2004. “'Why Don't I Know About These Women?': The Integration of Early Women Sociologists in Classical Theory Courses.” Teaching Sociology 32 (3): 252-263.

Tomasi, Luigi. 1998. The Tradition of the Chicago School of Sociology. Farnham, UK: Ashgate Publishing. 
Well, Ida. B. 2016. Southern Horrors and Other Writings: The Anti-Lynching Campaign of Ida B. Wells, 1892-19oo, 2nd edition, edited by J.J. Royster. Boston, MA: Bedford/ St. Martin's.

Women's Educational and Industrial Union. 1917. Studies in Economic Relations of Women. New York, NY: Longmans Green \& Company.

Young, Pauline V. 1932. Pilgrims of Russian-Town. Chicago, IL: University of Chicago Press. 